\title{
Special issue on cognition and learning technology
}

\section{J. Michael Spector}

(C) Association for Educational Communications and Technology 2010

The special issue of ETR\&D on Cognition and Learning Technology was originally scheduled to appear in the last issue of 2009-57(6). Five of the seven papers did appear in that issue. One paper appeared in the prior issue of ETR\&D_- "A Feedback Learning and Mental Models Perspective on Strategic Decision Making" by Carlos Capelo and João Ferreira Dias. The final paper in the special issue appears in this issue of ETR\&D"Highly Integrated Model Assessment Technology and Tools" by Pablo Pirnay-Dummer, Dirk Ifenthaler, and J. Michael Spector. Our apologies to the editors of the special issue, to the authors of all the special issue papers, and to readers for not having all of the papers involved in this special issue in a single issue as originally planned. 